\title{
Experimental Investigation Into the Condition of Insulated Rail Joints by Impact Excitation
}

\author{
M. Oregui ${ }^{1} \cdot$ M. Molodova ${ }^{1} \cdot$ A. Núñez ${ }^{1} \cdot$ R. Dollevoet ${ }^{1} \cdot$ Z. Li $^{1}$
}

Received: 11 June 2014 / Accepted: 27 May 2015 / Published online: 8 July 2015

(C) The Author(s) 2015. This article is published with open access at Springerlink.com

\begin{abstract}
This paper presents a feasibility study to determine if the health condition of Insulated Rail Joints (IRJs) can be assessed by examining their dynamic response to impact excitation. First, a reference dynamic behavior is defined in the frequency domain of $50-1200 \mathrm{~Hz}$ based on field hammer test measurements performed on a IRJ baseline (i.e., a set of IRJ without visible damage). Then, measurements on IRJs with different damage states are compared to the IRJ baseline response via the frequency response function (FRF) based statistical method. Three cases of IRJs are analyzed: a IRJ with a broken fastening, a IRJ with a damaged insulation layer and a IRJ with a rail top with plastic deformation. Combining hammer test measurements, hardness measurements and pictures of the IRJs, two frequency bands were identified as characteristic for damaged IRJs. In the identified high frequency band $(1000-1150 \mathrm{~Hz})$, the measured dynamic response with both a vehicle-borne health monitoring system and hammer tests shows a clear difference between the damaged IRJs and the IRJ baseline. Furthermore, different damage types may be able to be identified by examining the dynamic responses in the identified mid-frequency band $(420-600 \mathrm{~Hz})$. Further analysis over a larger number of IRJs may complete and support the promising results so that the information can be employed for the condition assessment and monitoring of IRJs.
\end{abstract}

Z. Li

z.li@tudelft.nl

1 Railway Engineering, Faculty of Civil Engineering and Geosciences, Delft University of Technology, Stevinweg 1, 2628 CN Delft, The Netherlands
Keywords Health monitoring - Insulated rail joint . Hammer test - Axle box acceleration measurement . Hardness test · Frequency response function based statistical method

\section{Introduction}

Insulated Rail Joints (IRJs) are railway track components where impact and high dynamic wheel-rail contact forces occur due to the rail discontinuity, see an example of an IRJ in Fig. 1. The frequent high impacts reduce up to five times the service life of IRJs with respect to continuously welded rails [1]. Although other methods to connect rails are more economical to maintain, IRJs are still needed because they are a fundamental component of non-GPS-based train positioning systems. In those systems, the railway network is divided into electrically insulated sections defined between IRJs so that sections can be "occupied" by a train (red light) or "free" of trains (green light). Thus, IRJs are safety-critical components because its malfunction can lead to failures of the signaling system and originate accidents. The timely monitoring of the health condition of IRJs is important because a significant number of the track circuit failures are originated at IRJs [2]; thus contributing considerably to the number of rail replacements [3]. Preventive maintenance of IRJs can improve safety and reduce the expensive costs of complete renewal of IRJs. Yet there is still no effective condition monitoring methods for assessment of the dynamic performance of IRJs. Monitoring methods have different advantages and disadvantages. Ultrasonic measurements work for deep cracks, whereas video image cannot capture invisible damage. In addition, some methods are labor intensive and often unsafe (e.g., bolt torque checking at the site). Hence, research oriented to the automatic monitor- 


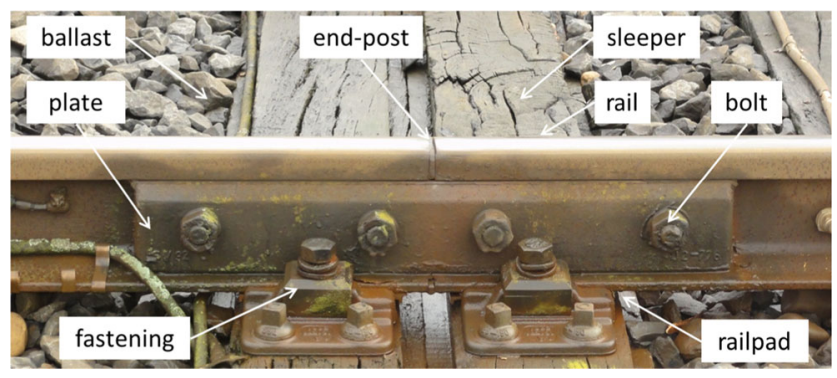

Fig. 1 Insulated rail joint and its components

ing of railway tracks conditions is important to improve the monitoring of the entire IRJ system and reduce costs.

Research conducted to understand the wheel-IRJ dynamic interaction can be employed to better understand the degradation of IRJs, so their service life can be extended with a timely maintenance. Many studies have approached the problem from the numerical point of view. Contrary to field measurements, the advantage of modeling is the flexibility to investigate the influence of different parameters under controlled simulations. There are different factors influencing the degradation of IRJs. For instance, regarding the vehicle, higher speed and higher axle loads accelerate the degradation of IRJ [3]. With respect to the track, higher wheel-rail impact forces occur with increasing misalignment between the rail ends [4-6], stiffer railpads [7], increasing deflection between the two rails [8-11, 43] and smaller Young's modulus of the end-post [12]. These studies have given an insight into the wheel-IRJ interaction. However, the disadvantage of the numerical approach is that the results are limited to the applicability of the models. The vehicle/wheel-IRJ/track interaction is a complex system. In many of the existing models, simplifications are made when representing the track, such as not accounting for the contact between rail and plates [3, 8, 12, 13] or simplifying the track to only one rail section [4, 6]. However, little is known about the consequences of these simplifications because, until recently, few measurements were available for the validation of IRJ models.

During the last years, different research groups have performed field measurements at IRJs. With those results, a better understanding of the wheel-rail contact forces and track displacements was obtained. In [14], the main focus was on quantifying the differences between straight tracks and IRJs; whereas the differences between different IRJ types is presented in [15]. The degradation of IRJs has been investigated by extensive field monitoring combining visual analysis with either settlement measurements in [16] or geometry measurements in [2]. Further useful information can be obtained from the analysis of degraded IRJs. For instance, characteristic frequencies related to the deterioration of IRJs could be derived, which might be employed for assessment and automatic monitoring of the health condition of IRJs.

In this paper, an experimental investigation of the vertical dynamic behavior of IRJs is presented. The contributions of this paper are threefold: (1) to gain a better insight into the dynamic behavior of IRJs so that the complex vehicle/wheel-IRJ/track system can be analized on a solid base, (2) to provide a measured nominal state that can be used for validation of numerical models of tracks with IRJs, and (3) to study the feasibility to assess the health condition of IRJs by examining their dynamic response via a frequency response function (FRF) based statistical method. For this purpose, field hammer test measurements have been performed at different IRJs with two hammer sizes so that a wide frequency range is covered. First, an IRJ baseline state is determined and a reference dynamic behavior is defined. Then, IRJs with different damage conditions are compared to the IRJ baseline state via the FRF-based statistical method. The investigation is complemented with hardness measurements of the rail top, visual inspection (i.e. pictures) and dynamic-response-based vehicle-borne measurements (i.e. from an Axle Box Acceleration (ABA) system).

\section{Field Measurements at IRJs}

\section{Characterizing the Dynamics of the Railway Track by Hammer Test Measurements}

In railway engineering, hammer test measurements have been used for two main purposes. First, the dynamic behavior of the track or track components can be characterized and insight can be gained by examining the frequency response function obtained [17-19]. Second, parameters of the track that are difficult to directly measure but are required for modeling, can be derived. These parameters are usually the stiffness and damping of the railpad, which is the resilient component between the rail and the sleeper, and the stiffness and damping of the ballast, which is the stone bed of the track (see the components in Fig. 1). The operational and environmental conditions can cause the ballast stones to become loose and to deteriorate the railpads, resulting in lower stiffness and damping values than the nominal values [18]. The in-service parameters of the railpad and ballast are typically derived by numerically reproducing the response of the track to impact excitation (i.e. hammer test) [20-22].

Different hammer and hammer tip types are used depending on the frequency range of interest. The low frequencies are investigated with heavy hammers and soft tips, whereas the high frequencies are analyzed with light hammers and hard tips [23]. In this paper, two hammer sizes have been 


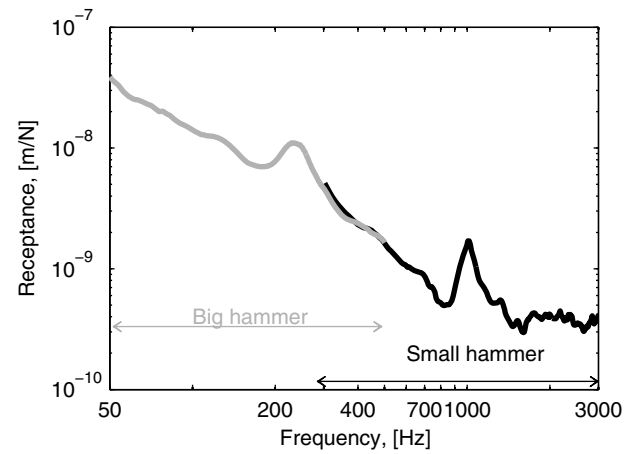

(a)

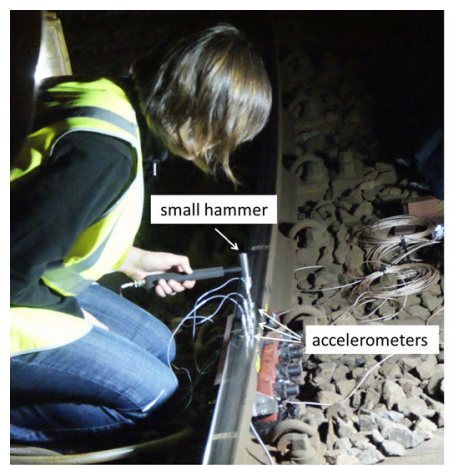

(b)

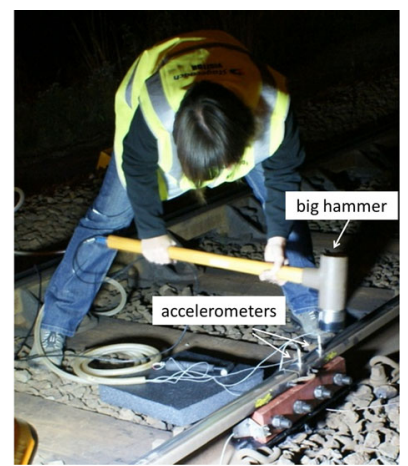

(c)

Fig. 2 (a) Measured receptance functions with small and big hammer and their overlap, and field hammer test measurements with (b) the small hammer and (c) the big hammer

used. For the high frequency, a Bruël \& Kjær 8206 hammer and a hard plastic tip of $12 \mathrm{~mm}$ is used [24] (called the small hammer). For the low frequency, a 086D50 ICP impact hammer with a plastic tip of $76 \mathrm{~mm}$ is employed [25] (called the big hammer). A hard tip, yet softer that the tip of the small hammer, is used in the big hammer so that the frequency ranges of the two hammers overlap (see Fig. 2(a)). As a result, the frequency range is defined between 50 and $3000 \mathrm{~Hz}$, which includes the frequencies of interest [8, 9]. The low frequency limit is fixed at $50 \mathrm{~Hz}$ because the big hammer is not able to fully excite the ballast and subgrade which are the track components that dominate the dynamic behavior of the track at low frequency [26]. The high frequency limit is determined at $3 \mathrm{kHz}$ because reliable data can be obtained up to $3 \mathrm{kHz}$ with the small hammer (i.e. -10 $\mathrm{dB}$ drop at approximately $3 \mathrm{kHz}$ ) [23]. A hammer test with the small hammer and one with the big hammer are shown in Figs. 2(b) and (c) respectively.

In the field hammer test measurements presented in this paper, the same procedure was followed for all the tests. A rail section was vertically excited on the top multiple times $F_{i}(t)$ and the response was measured with an uni-directional accelerometer that was placed on the rail top with a magnet, $a_{i}(t)$, see a schematic representation of an example in Fig. 3. The input and output data were recorded with a sampling frequency of $20 \mathrm{kHz}$.

The excitation and measurement locations were the same for hammer tests carried out with the small hammer. Four configurations were investigated, which corresponded to the

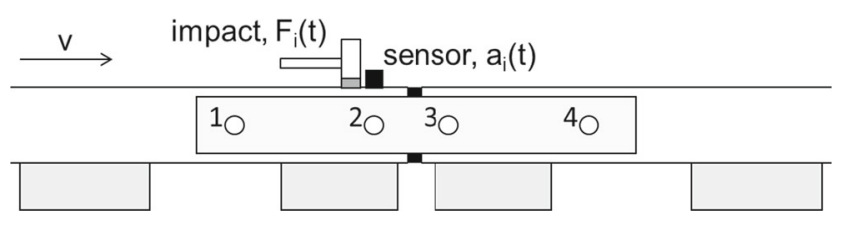

Fig. 3 An schematic drawing of the hammer test measurements on a IRJ for the configuration $\mathrm{P} 2$ rail above the four bolts. If the bolts are numbered from one to four in the direction of the traffic, the excitation configurations are called P1, P2, P3 and P4 respectively from now on. As an example, the P2 configuration for the impact $i$ is shown schematically in Fig. 3. When performing the hammer test measurements with the big hammer, the rail could not be both excited and measured above a certain bolt because of the $76 \mathrm{~mm}$ diameter of the hammer, which covers almost half of the $200 \mathrm{~mm}$ distance between two bolts of the same half. Therefore, it was decided to measure on the rail top above the bolt of interest and excite the rail between the two bolts of that half of the IRJ. For instance, the rail was excited between the first and the second bolts and the response was measured above the first bolt for the P1 configuration and above the second bolt for the P2 configuration.

The post-processing of the measured data is schematically shown in Fig. 4. In each configuration, five impacts were applied and measured both force and acceleration (input and output, respectively). By matching the maximum force values of the five impacts (time shift $\tau_{i}$ ), the average force and acceleration $(F(t)$ and $a(t)$, respectively) were used to reduce the random error. In the case the averaged measured signals were shorter than $1.2 \mathrm{~s}$, zeros were added to the signal so that a better frequency resolution was obtained in the frequency domain. Also, a low-pass filter with the cut-off frequency of $10 \mathrm{kHz}$ was applied to avoid aliasing. The transformation into the frequency domain was performed by Fast Fourier Transform with a rectangular window of 1000 measurement point wide. The accelerance function $H_{a}(f)$ was calculated as follows:

$$
H_{a}(f)=\frac{S_{a F}(f)}{S_{F F}(f)}=\frac{\sum_{n-1}^{N} \sum_{m-1}^{N-m-1} a[m+n] F[m] e^{-j 2 \pi f n}}{\sum_{n-1}^{N} \sum_{m-1}^{N-m-1} F[m+n] F[m] e^{-j 2 \pi f n}}
$$


Fig. 4 Post-processing procedure of the measured data
Measurements
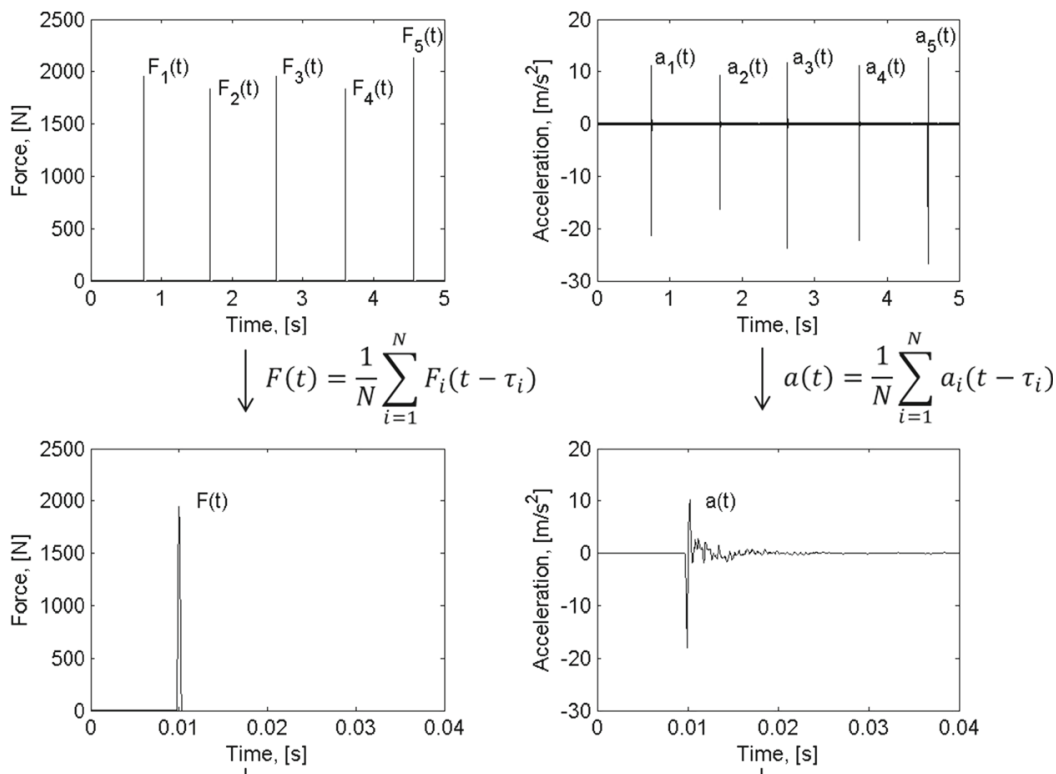

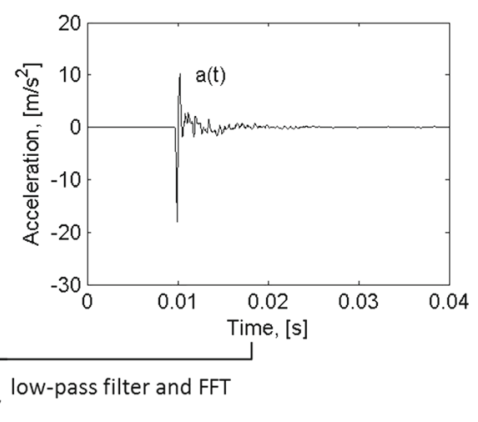

Frequency domain response

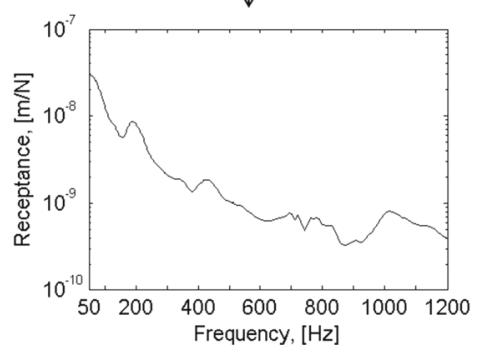

where $S_{a F}$ is the cross-spectrum between the force and the acceleration, and $S_{F F}$ the autospectrum of the force. In this manner, the effect of the noise was minimized at the output [27]. Then, the receptance function $H_{d}(f)$ was calculated as follows:

$H_{d}(f)=\frac{H_{a}(f)}{(2 \pi f)^{2}}$

where $f$ is frequency. The measured receptance functions show the response of IRJs for vibrations in terms of displacement over force as a function of vibration frequencies. From the receptance function, characteristic frequencies of IRJs can be identified at the resonances and antiresonance by analyzing peaks and dips, respectively. Also, the receptance function provides a way of comparing IRJs. Significant differences in characteristic frequencies indicate differences in the structure of the IRJs because the dynamic response of the track is the result of the dynamic behavior of its components and the interaction between them.

\section{Obtaining Information About the Wheel-Rail Contact Forces from Hardness Measurements}

Performing hardness measurements of the rail top is an indirect way of obtaining information about the impact and dynamic contact forces between the wheel and the rail. Hardness is a time variable phenomenon so that each passage of wheel would change the hardness distribution on the rail top. However, in the case of IRJs, wheel-rail impact always occurs after the wheel passage over the gap; therefore, the wheel-rail dynamics are excited very similarly each time. If the wheel-rail contact forces are high enough to cause plastic deformation, a permanent wave pattern may develop at a dominant frequency of the wheel-rail interaction. Consequently, even higher wheel-rail contact forces would occur [9]. Under these conditions, the deterioration of the IRJ would accelerate and the service life would shorten. Thus, an IRJ with a hardness wave pattern on the rail top after the gap means that the IRJ is already captured in an accelerated deterioration process.

In the field monitoring presented in this paper, the hardness of the rail top was measured every $5 \mathrm{~mm}$ along three 
lines in the running band, in the cases in which the wavelength were not visible. The middle line is approximately in the middle of the running band, whose position varied for the different IRJs. The inner and outer lines are separated $5 \mathrm{~mm}$ from the middle line. A DynMIC 34247 was used in combination with a self-developed ruler-guide as shown in Fig. 5(a). An example of the three hardness measurement lines denoted by inner, middle and outer is shown in Fig. 5(b).

\section{Track Site}

The field measurements were performed at the WeertEindhoven main line in the Netherlands. Approximately $85 \%$ of the traffic is for passenger transport with two double deckers and two sprinters running within the hour. The traffic at the test track site is one-directional with a maximum allowed speed of $140 \mathrm{~km} / \mathrm{h}$. In the track, UIC54 rails with $1 / 40$ inclination were supported by NS90 monoblock sleepers every $0.6 \mathrm{~m}$ except in the proximity of IRJs. As shown in Fig. 1, all the IRJs were supported with sleepers to reduce the deflection of the joint. The wooden sleepers introduce damping to the system, which helps in the absorption of vibrations caused by the impact when a wheel rolls over the discontinuity. A set of different IRJs with the same type of IRJ were examined along $2 \mathrm{~km}$ of the two adjacent straight tracks. There was no information available about the date when the IRJs were installed in the track. Next, a method to determine a baseline state for IRJs is presented in "Defining the IRJ Baseline" section.

\section{Defining the IRJ Baseline}

The IRJ baseline was defined based on a set of reference IRJs which were combined by applying the principle of the process-monitoring technique called control charts [28]. In these charts, the quality of a monitored process is controlled by limits that are based on $m$ preliminary data via sample mean and sample variance thus considering the variability of the process to monitor. This concept was adapted to railway tracks in [29]; the baseline was defined as an average of hammer test measurements at locations without damage to the naked eye. Finding a method to select reference locations with a higher certainty of their health is part of future work.

Thus, the variability between IRJs was considered by selecting one group of $m$ reference IRJs without damage to the naked eye. Responses far from the average group are eliminated from the statistics. Then, the sample mean and sample variance were calculated according to equations (3) and (4), respectively.

$\hat{J}_{0}=\frac{1}{m} \sum_{i=1}^{m} \hat{J}_{i}$

$\hat{\sigma}_{J 0}^{2}=\frac{1}{m-1} \sum_{i=1}^{m}\left(\left|\hat{J}_{i}\right|-\left|\hat{J}_{0}\right|\right)^{2}$

where, in this study, $\hat{J}_{i}$ is either the hardness (see "Hardness Tests for the IRJ Baseline" section) or the receptance function according to equation (2) (see "Characterizing the Dynamics of the Railway Track" by Hammer Test Measurements"), for measurement $i$.

In this paper, 12 reference IRJs were found under the same working conditions in the test track site and used to define the baseline. The 12 IRJs were in-service for a maximum of three years. The track components did not have visible cracks or defects and the end-post seemed to be in a good condition (see one of the reference IRJs in Fig. 6). Furthermore, the reference IRJs seemed to be properly supported as the stones in the neighborhood of the supporting wooden sleepers were not white. At loosened supports, the sleeper gains freedom of movement in the ballast bed and consequently, the interaction between the stones and the sleeper increases resulting in worn stones and white stone dust. In view of the good condition of the 12 reference IRJs, the 12 reference IRJs were considered a substantial basis for the baseline.

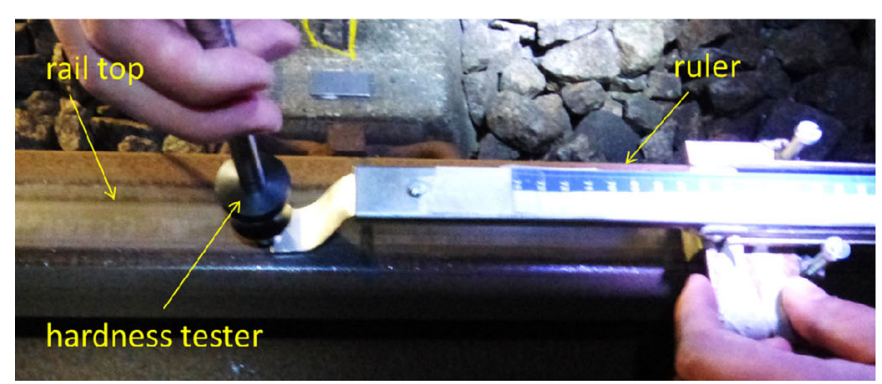

(a)

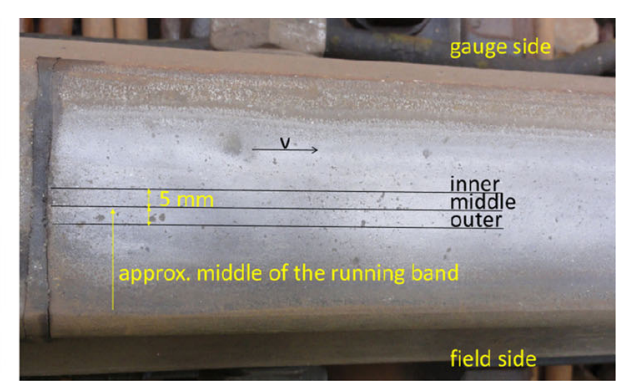

(b)

Fig. 5 (a) Field hardness measurement on the rail top (b) An example of the three hardness measurement lines along the rail 


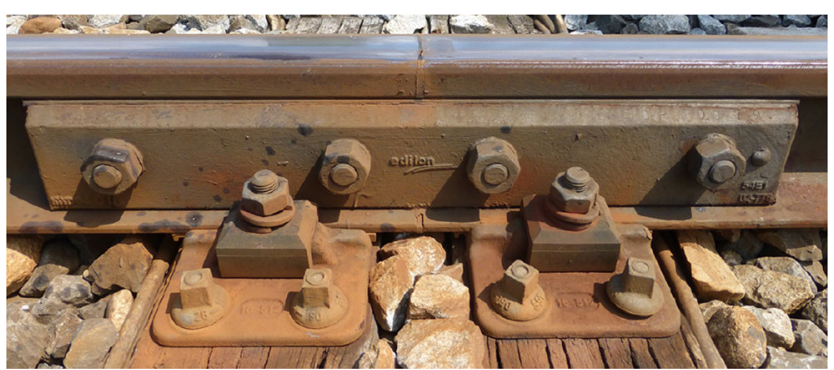

Fig. 6 A reference IRJ

\section{Hardness Tests for the IRJ Baseline}

The hardness of the rail top immediately after the discontinuity was measured along $120 \mathrm{~mm}$ for the 12 reference IRJs forming the baseline. Figure 7 shows the average values of the three hardness measurements of each of the IRJs, the mean hardness of the 12 reference IRJs $\left(\hat{R}_{0}\right)$ and one standard deviation with respect to the mean $\left(\hat{R}_{0} \pm \hat{\sigma}_{R 0}\right)$. The scatter of the hardness values is in agreement with the hardness measurements at the beginning of the monitoring of new IRJs presented in [2]. The mean $\hat{R}_{0}$ only shows the development of a short wave pattern immediately after the discontinuity (see the first $15 \mathrm{~mm}$ in Fig. 7). For further distances, the baseline is in good condition in terms of rail head deformation.

\section{Hammer Tests for the IRJ Baseline}

Defining the reference characteristic dynamic behavior of IRJs is not straightforward. Although the structure is symmetric with respect to the discontinuity, the service conditions (i.e. one-direction traffic) may influence the IRJ differentiating the dynamic behavior of the track before and after the discontinuity. As trains always run in the same direction on the track of this case study, only the rail after the discontinuity is subjected to impact forces, which

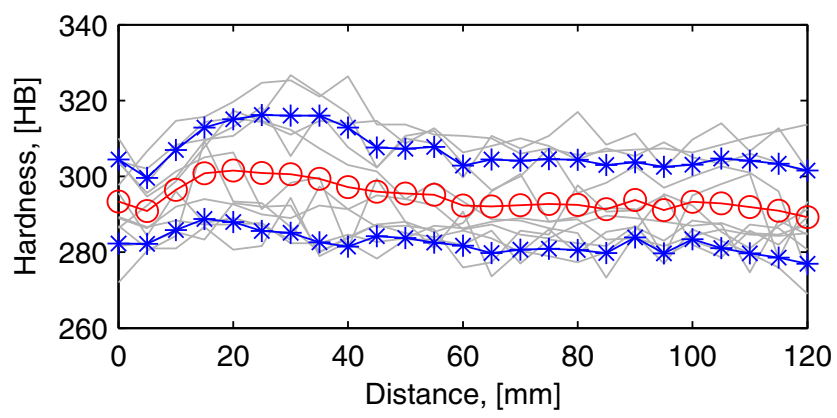

Fig. 7 Measured hardness after the discontinuity: (o) the mean hardness of the IRJ baseline $\hat{R}_{0},(*)$ one standard deviation with respect to the mean $\left(\hat{R}_{0} \pm \hat{\sigma}_{\mathrm{R} 0}\right)$, and (-) average hardness measurements of the 12 reference IRJs may affect the track components such as the rail, the interaction between the rail and the connecting plates, and the condition of the support where the rail end is supported and the consecutive supports $[14,16]$. The symmetry of the dynamic behavior of IRJs with respect to the discontinuity is studied in "Symmetry of IRJs with respect to the discontinuity" section.

Furthermore, the IRJ is an heterogeneous structure. The distance between the measured response, end-post and holes may significantly influence the resulting dynamic response of the track. The effect of the structure of the IRJ on its dynamic behavior is investigated in "Influence of the structure of the IRJ" section.

\section{Symmetry of IRJs with respect to the discontinuity}

The symmetry of the vertical dynamics of IRJs with respect to the discontinuity is studied by comparing measurements of symmetric hammer tests. The measured receptance functions of the P1 and P4 configurations are shown in Fig. 8(a). The frequency response functions differ in the frequency ranges of 950 and $1200 \mathrm{~Hz}$, and of 1700 and $3000 \mathrm{~Hz}$. The measured receptance functions of the configurations P2 and P3 are shown in Fig. 8(b) and a different behavior is observed between 1200 and $3000 \mathrm{~Hz}$. These differences between the two halves of the IRJs suggest that the impact and high wheel-rail contact forces had already caused some initial changes in the reference IRJs. In the frequency range of $1200-3000 \mathrm{~Hz}$, the reference IRJs are not dynamically symmetric. The passages of wheels over the IRJ have already caused small changes in the rail and railpad which dominate the dynamic response of the track in this frequency range $[17,30,31]$. Therefore, the receptance function of this IRJ baseline should be limited up to $1200 \mathrm{~Hz}$.

The receptance functions with the $\mathrm{P} 1$ and $\mathrm{P} 4$ configurations disagree on a second frequency range, which is between 950 and $1200 \mathrm{~Hz}$. A peak at $1040 \mathrm{~Hz}$ is seen for the P1 configuration; in contrast, the peak is not observed for the P4 configuration. $1040 \mathrm{~Hz}$ corresponds to the pinpin resonance frequency of the track investigated [29]. In this mode, the rail vibrates with its nodes on the supports so that it strongly depends on sleeper distance and rail properties [17], and also on railpad properties [21, 30]. It is believed that the occurrence of the widespread rail defect short pitch corrugation is directly related to the pin-pin phenomenon [32]. In the case of the reference IRJs, the measurements suggest that the high impact and contact forces between the wheel and the rail altered the condition of the supports immediately after the discontinuity. Thus, a baseline receptance functions should be defined based on the measurements carried out on the first half of the IRJ (i.e. $\mathrm{P} 1$ and $\mathrm{P} 2$ configurations) because the impact has a smaller 


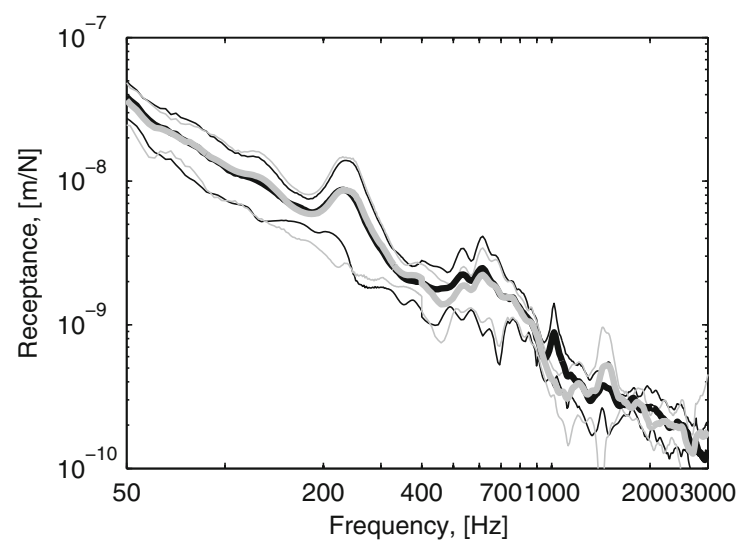

(a) P1 (-) and P4 (-) configurations

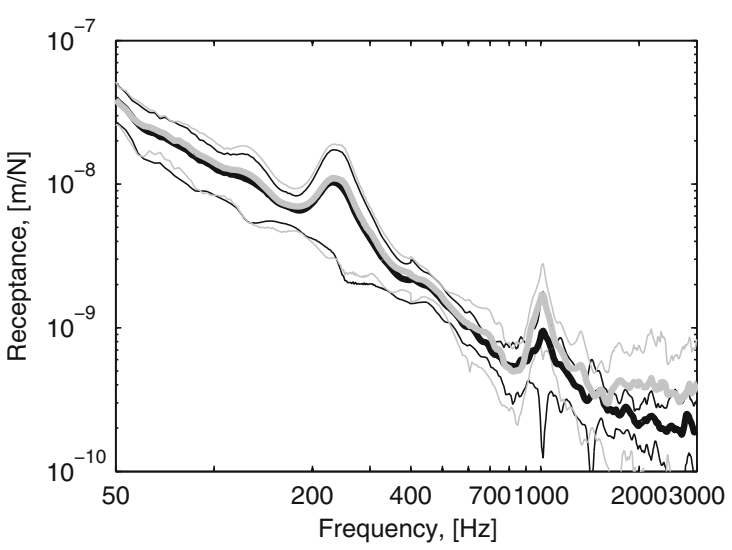

(b) P2 (一) and P3 (-) configurations

Fig. 8 Measured receptance functions of the baseline IRJ at different configurations: (a) (—) the average P1 $\left(\hat{H}_{d 0}(f)\right)$, $(-)$ one standard deviation with respect to the average $\mathrm{P} 1\left(\hat{H}_{d 0}(f) \pm \hat{\sigma}_{0}(f)\right)$, and $(-)$ the average $\mathrm{P} 4\left(\hat{H}_{d 0}(f)\right),(-)$ one standard deviation with respect to the average $\mathrm{P} 4\left(\hat{H}_{d 0}(f) \pm \hat{\sigma}_{0}(f)\right)(\mathbf{b})(-)$ the average $\mathrm{P} 2\left(\hat{H}_{d 0}(f)\right),\left(\_\right)$one standard deviation with respect to the average $\mathrm{P} 2\left(\hat{H}_{d 0}(f) \pm \hat{\sigma}_{0}(f)\right)$, and $(-)$ the average $\mathrm{P} 3\left(\hat{H}_{d 0}(f)\right),(-)$ one standard deviation with respect to the average $\mathrm{P} 3\left(\hat{H}_{d 0}(f) \pm \hat{\sigma}_{0}(f)\right)$

effect on the components of the first half than on the ones of the second half.

In summary, it appears that the dynamic behavior of the reference IRJs is not symmetric with respect to the discontinuity. Although the structure is geometrically symmetric, the fact that the track is one-directional leads to different dynamic behaviors of the two ends of the rail joint. Nevertheless, in the frequency range of $50-1200 \mathrm{~Hz}$ the receptance functions of the symmetric excitation configurations agree or the differences are understood. A IRJ baseline is assumed to be symmetric geometrically and dynamically, this is, the $\mathrm{P} 1$ configuration is equivalent to the $\mathrm{P} 4$ configuration, whereas the P2 configuration is equivalent to the $\mathrm{P} 3$ configuration. For the baseline, the configurations are denoted by the letter $\mathrm{N}$ instead of $\mathrm{P}$. Thus, from now on, the $\mathrm{N} 3$ and $\mathrm{N} 4$ will be used as the reference configurations based on the $\mathrm{P} 2$ and P1 configurations, respectively. Thus, the baseline receptance functions are shown in Fig. 9.

\section{Influence of the structure of the IRJ}

The influence of the structure of the IRJ on the measured dynamics is investigated by comparing the measured receptance functions of the N3 and N4 configurations. As shown in Fig. 9, the IRJ baseline response is practically identical for frequencies lower than $500 \mathrm{~Hz}$ and between 900 and $1200 \mathrm{~Hz}$. The subgrade, ballast and sleeper are the track components that dominate the dynamic behavior of the track at frequencies lower than $500 \mathrm{~Hz}[17,26]$, whereas the sleeper distance, rail and railpad mainly determine the dynamic response of the track in the frequency range of 900 and $1200 \mathrm{~Hz}[17,31]$. Between 500 and $900 \mathrm{~Hz}$, the receptance functions of the $\mathrm{N} 3$ and $\mathrm{N} 4$ configurations are significantly different. This difference suggests that the fre- quency range of 500-900 $\mathrm{Hz}$ is related to the joint because the two configurations have a different distance to the rail end, the plates ends, the support and the bolt holes.

Therefore, the dynamic response depends on the excitation configuration. This is generally the case in a discretely supported track, which depends on the excitation configuration when defining its characteristic behavior [20-22]. Typically, two characteristic curves are defined and are known as the on-support and mid-span frequency response functions. Numerically reproducing the on-support and midspan curves is a widespread method to validate track models and to derive track parameters by fitting simulations to the measurements. The same concept could be applied for IRJs; this is, the N3 and N4 curves shown in Fig. 9 could be used

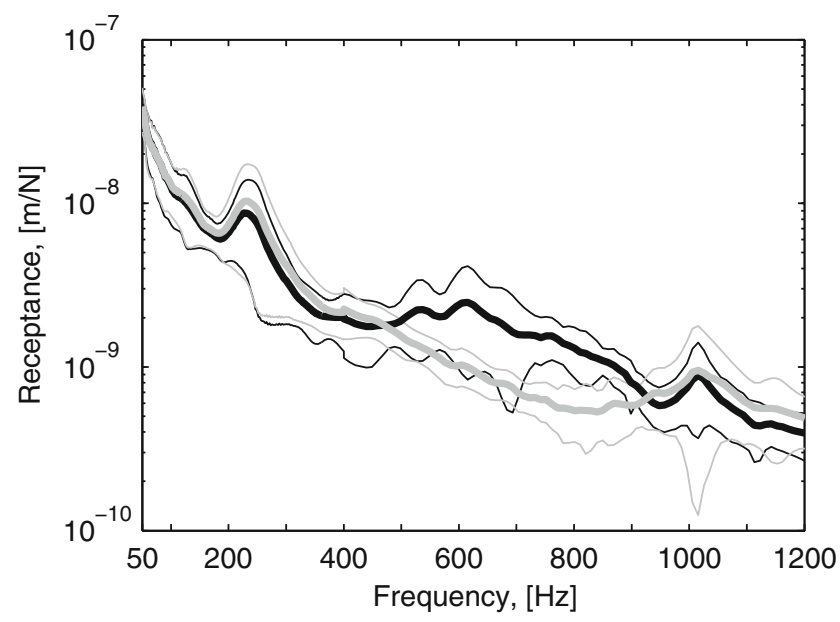

Fig. 9 Measured receptance functions of the baseline IRJ: (-) the average $\mathrm{N} 3\left(\hat{H}_{d 0}(f)\right),(-)$ one standard deviation with respect to the average $\mathrm{N} 3\left(\hat{H}_{d 0}(f) \pm \hat{\sigma}_{0}(f)\right)$, and $(-)$ the average $\mathrm{N} 4\left(\hat{H}_{d 0}(f)\right)$, $(-)$ one standard deviation with respect to the average $\mathrm{N} 4\left(\hat{H}_{d 0}(f) \pm\right.$ $\left.\hat{\sigma}_{0}(f)\right)$ 
for the validation of a reference IRJ model and for deriving parameters of a track vibration model in the proximity of a reference IRJ.

\section{FRF-Based Statistical Method}

For investigating damage at IRJs by analyzing the dynamic response, we use the non-parametric time-series method called Frequency Response Function (FRF) based statistical method [33, 34]. The method compares the structure under study to a healthy state, in our case the IRJ baseline, so that characteristic frequencies of damaged IRJs may be identified. This method was successfully applied to squats, a short wave rail surface defect, in [29]. Unlike parametric time-series methods, non-parametric time-series methods do not require a numerical model to fit to the measured response; therefore, the results obtained do not depend on the accuracy of the model to reproduce the measurements. Furthermore, the deterioration state is assessed by applying statistical tools, thus removing the subjectivity introduced by human operators from the decision-making process. Additionally, the FRF-based statistical method considers the inherent uncertainty of the track introduced by measurements repeatability [29] or variability of the track ("Hammer Tests for the IRJ Baseline" section).

The FRF-based statistical method is applied in two steps. First, FRF magnitudes are evaluated via Welch estimates [35]. For the structure under study, the FRF estimate is denoted by $\hat{H}_{d u}(f)$ at frequency $f$, whereas for the healthy structure $\hat{H}_{d 0}(f)$ is used. Second, a binary composite hypothesis test is applied [33] so that the FRF magnitude of the current state of the structure $\left(\left|\hat{H}_{d u}(f)\right|\right)$ is compared to the healthy (i.e non-damaged) structure $\left(\left|\hat{H}_{d 0}(f)\right|\right)$. Next, the $Z$ statistic is defined for each $f$ in (5) for the statistical decision making:

$Z(f)=\frac{\left|\left(\left|\hat{H}_{d 0}(f)\right|-\left|\hat{H}_{d u}(f)\right|\right)\right|}{\sqrt{2 \hat{\sigma}_{0}^{2}(f)}}$

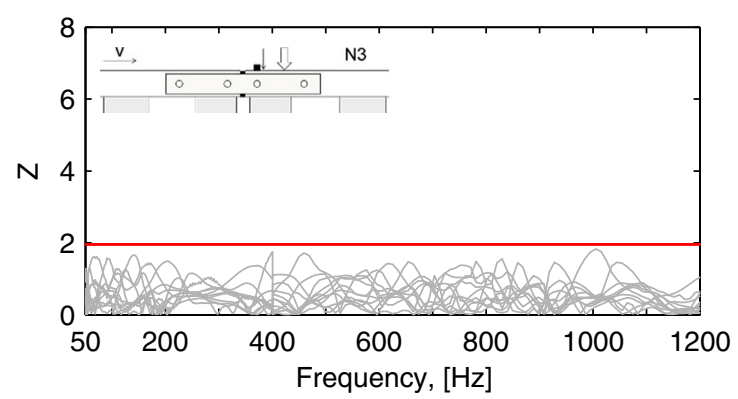

(a) N3 configuration
In our case, the healthy state $\left(\left|\hat{H}_{d 0}(f)\right|\right)$ and its variance $\left(\hat{\sigma}_{0}^{2}(f)\right)$ are determined as the IRJ baseline of "Hammer Tests for the IRJ Baseline" section. It is assumed that the difference between the FRF estimators follows a Gaussian distribution as suggested in [36].

The statistical test is defined to assess if the deviations between the current state of the structure and the healthy structure are statistically significant. For this purpose, the $Z$ statistic is examined according to equation (6) at the selected $\alpha$ risk level, which is the probability of having a false alarm.

$$
\begin{aligned}
Z(f) \leq Z_{1-\frac{\alpha}{2}}(\forall f) & \Rightarrow \text { Healthy structure } \\
\text { else } & \Rightarrow \text { Damaged structure }
\end{aligned}
$$

with $Z_{(1-\alpha / 2)}$ designating the critical point of the standard normal distribution at $1-\alpha / 2$.

Figure 10 shows the application of the FRF-based statistical method to the IRJ baseline. The chosen $\alpha$ risk value was 0.05 , which implies a $5 \%$ probability for a false alarm to occur. For this value of $\alpha$, the statistical limit $Z_{\text {lim }}$ is 1.96 (see equation (6)). All measurements of the baseline are below the statistical limit $Z_{\text {lim }}$ (i.e. horizontal line in Fig. 10).

\section{Damaged IRJs}

In addition to the reference IRJs, different IRJs were examined in the track site located in Weert, the Netherlands. For the analysis, three damaged IRJs were considered. In two of the IRJs, damage on some of the track components were visible (Figs. 11 and 14). In the third IRJ, the only sign of deterioration was the plastic deformation of the rail top after the discontinuity (Fig. 17).

\section{IRJ with a Broken Fastening}

The first damaged IRJ examined had a fastening broken in the supporting sleeper after the discontinuity, as shown in the right close-up of Fig. 11. A broken fastening means a

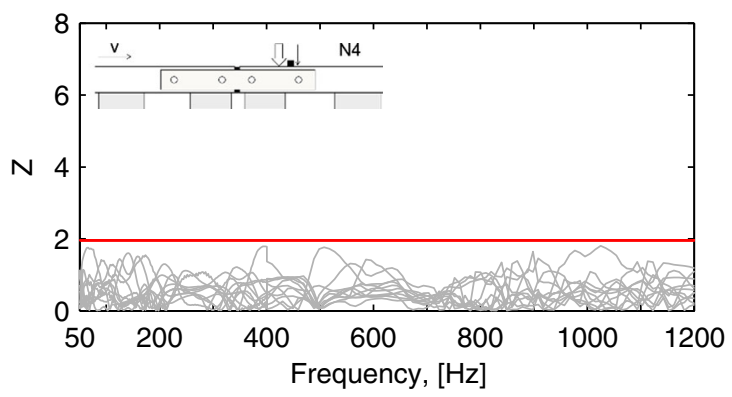

(b) N4 configuration

Fig. $10 Z$ test at the IRJ baseline with (-) $Z_{\text {lim }}$, and (-) $Z_{\text {measurements }}$ at the reference IRJs 


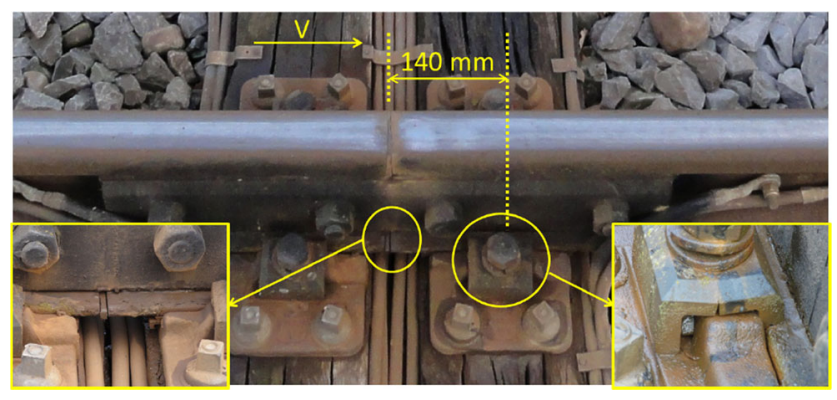

Fig. 11 An insulated rail joint with the fastening broken in the supporting sleeper after the discontinuity

relaxation of the restraints on the rail. The looseness of the end-post was also visible at the rail foot. The end-post was slightly thinner than the gap between the rail ends and it was popping out (see left close-up of Fig. 11).

\section{Hardness measurement}

The wavelength of the wave pattern on the rail top seen in Fig. 11 was quantified by the hardness measurements, which are shown in Fig. 12. Contrary to the reference case (Fig. 7), almost the same hardness value was measured in the first $40 \mathrm{~mm}$ immediately after the discontinuity along the three measurement lines, see Fig. 12(a). The very good agreement between the three measurement lines for the first wave is caused by the impact immediately after the gap which widened the running band. The average of the three hardness measurements shows peaks at $20 \mathrm{~mm}$ and $55 \mathrm{~mm}$, so that the wavelength of the wave pattern is $35 \mathrm{~mm}$ (see Fig. 12(b)).

At a further distance, the agreement between the three measurements is less evident because the running band is narrower, which means the the stresses drop quickly out of its center. The hardness measurement at the outer line shows the wave pattern the clearest (see $x$ in Fig. 12(a)). Between 20 and $140 \mathrm{~mm}$, the wavelength varies between 35 to $45 \mathrm{~mm}$. The scatter of the wavelength should mainly be due to the $5 \mathrm{~mm}$ interval of the hardness measurement.
This wavelength is similar to those of corrugation [20] and of the wave pattern caused by squats [37] in the Dutch network. At $140 \mathrm{~mm}$, the three measurements show almost the same hardness value, which possibly indicates the effect of the broken fastening at $140 \mathrm{~mm}$. This change in stiffness in the structure of the IRJ caused high wheel-rail contact forces that result in high stresses and consequently, plastic deformation and hardening of the rail top.

The average hardness profiles of the IRJ baseline with that of the IRJ with the broken fastening are compared up to $120 \mathrm{~mm}$ after the gap in Fig. 12(b). Almost all the hardness values of the IRJ with broken fastening are higher than one standard deviation from the average. Based on this hardness difference, one may assume that the IRJs forming the baseline are relatively new with respect to the IRJ with the broken fastening. The fluctuation of hardness value is also significantly larger for the IRJ with the broken fastening than for the IRJ baseline; the difference between the largest and smallest hardness values are approximately $35 \mathrm{HB}$ and $10 \mathrm{HB}$ respectively. Larger varying hardness value mean larger stresses on the rail top, which would have been caused by larger dynamic wheel-rail contact forces. The increase in the dynamic contact forces were induced by the deterioration of the IRJ, such as the wave pattern on the rail top and the broken fastening.

\section{Hammer measurement}

To further investigate the dynamics of the IRJ, the hammer test measurements were analyzed via the FRF-based statistical method. The $Z$ statistics are shown in Fig. 13. For both $\mathrm{N} 3$ and N4 configurations, the $Z$ statistics cross the statistical limit $Z_{\text {lim }}$ at $1040 \mathrm{~Hz}$ which corresponds to the pin-pin resonance frequency of the test track site [29]. This frequency may also be related to the occurrence of the wave pattern on the rail top. The wavelength of the measured hardness profile is between 35 and $45 \mathrm{~mm}$ (Fig. 12(a)), which combined with the nominal train speed of 140 $\mathrm{km} / \mathrm{h}$, results in vibrations at the frequency range of 865 $1111 \mathrm{~Hz}$.

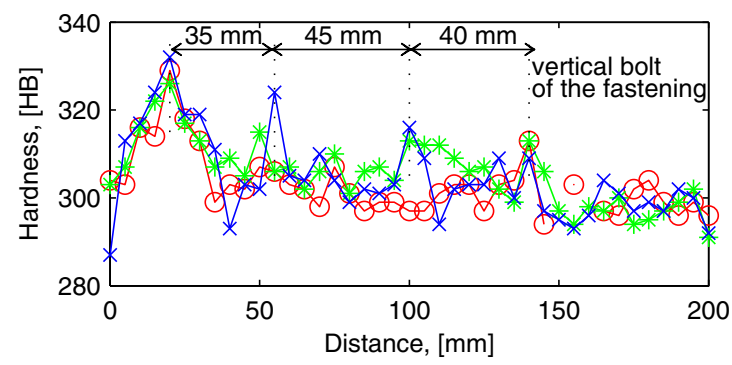

(a)

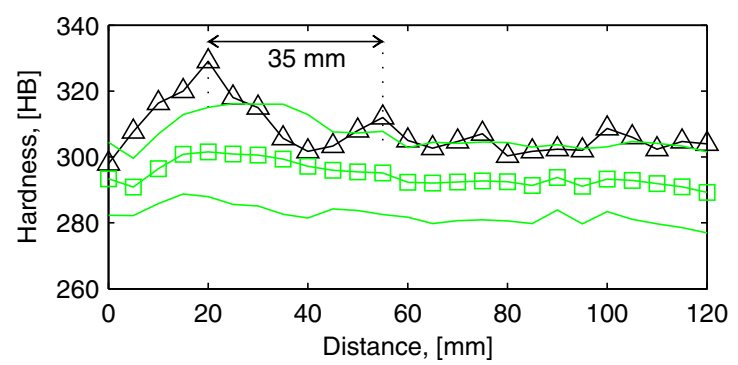

(b)

Fig. 12 Measured hardness after the discontinuity at the IRJ with the broken fastening (a) along the inner $(\circ)$, middle $(*)$ and outer lines $(\times)$ indicated in Fig. 5(b), (b) the average of the three measurements $(\triangle)$ and the average of the IRJ baseline ( $\square$ ) from Fig. 7 


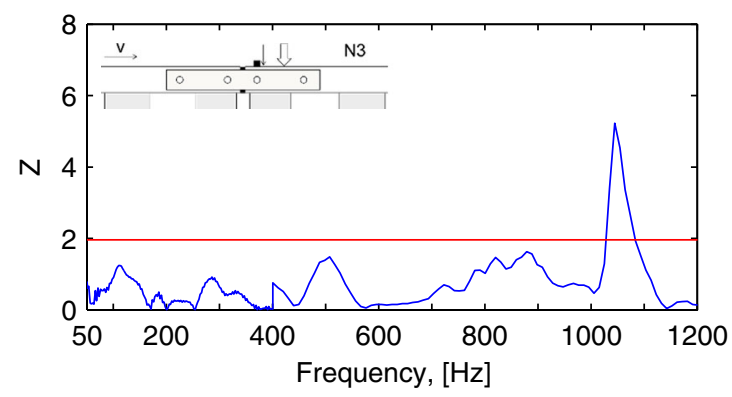

(a) N3 configuration

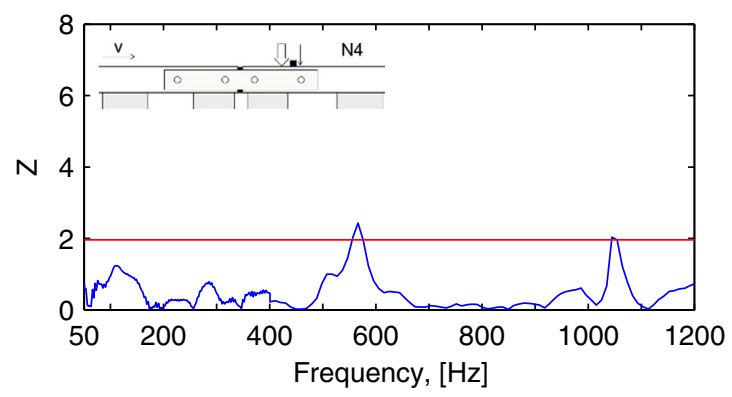

(b) N4 configuration

Fig. $13 Z$ test at the IRJ with broken fastening with (-) $Z_{\text {lim }}$, and (-) $Z$ at the IRJ with broken fastening

For the N4 configuration, the FRF-based statistical method also identifies $566 \mathrm{~Hz}$ as a possible frequency related to the IRJ with broken fastening. This type of damage affects the interaction between the sleeper and the rail, which is one of the dominant phenomena defining the dynamic response of the track in the medium frequency range $[17,21,30,31]$.

\section{IRJ with a Damaged Insulation Layer}

The second damaged IRJ examined showed a gap between the rail ends that is significantly wider than the width of the end post as shown in the close-up of the left in Fig. 14. Furthermore, the fastening before the discontinuity was broken as shown in the close-up of the right in Fig. 14. Notice that in this case the traffic is from right to left. Also, the ballast bed in the proximity of the IRJ showed a white color, indicating a loosened support.

IRJs are often prefabricated but this IRJ was most probably assembled in the site. Some signs of the site-assembling were the tape that was applied at the end of the plates to keep the insulating material between the rail and the plates, and the extra washers on the bolts to improve the tightening of the bolts to the plates. Moreover, extra holes were made in the plates to fit to the existing holes in the rail. These

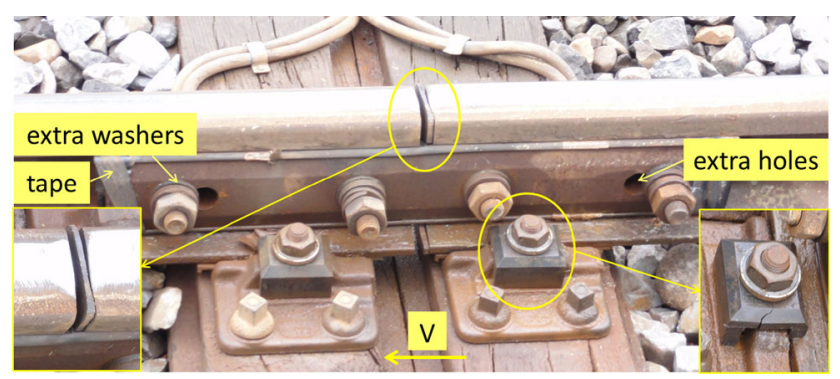

Fig. 14 An insulated rail joint with a damaged insulation layer between the rail ends and a broken fastening in the supporting sleeper before the discontinuity indicate that the IRJ assembly underwent a major maintenance. However, this maintenance action did not stop the degradation of the IRJ and the whole IRJ should soon be replaced to guarantee the electrical insulation between the track sections.

\section{Hardness measurement}

The hardness measurements on the rail top are shown in Fig. 15. In this case, the measurements were performed over $100 \mathrm{~mm}$ along the rail. The comparison of these hardness profiles with the ones of the IRJ baseline shows that most of the values are within one standard deviation from the average IRJ baseline hardness. This closeness to the baseline is unexpected in view of the hardness measurements of the IRJ with broken fastening in "Hardness measurement" section. A similar or larger hardness difference was expected at the IRJ with the damaged insulation layer compared with that at the IRJ with the broken fastening because the damage is more severe. However, the hardness fluctuation at the IRJ with the damaged insulation layer is $33 \%$ smaller. This difference may be explained by the grinding marks on the rail top. The fact that the grinding marks were still visible and the measured wave pattern showed the typical wavelength after grinding of 10-20 mm [32] (see Fig. 15(b)), indicate that the rail top was ground some time near the measurement campaign. Thus, a layer of the rail top was most probably removed clearing away hardened material.

\section{Hammer measurement}

The responses of the IRJ with a damaged insulation layer and the IRJ baseline were compared via the FRF-based statistical method. The $Z$ statistics for the N3 and N4 configurations are shown in Fig. 16(a) and (b), respectively. For the two configurations, the $Z$ statistic crosses the statistical limit $Z_{\text {lim }}$ at approximately 380 and $1040 \mathrm{~Hz}$. The crossing at approximately $380 \mathrm{~Hz}$ may be related to a loosened support as the presence of white stones in the track suggests. Bellow $500 \mathrm{~Hz}$, the ballast, sleeper and their interaction 


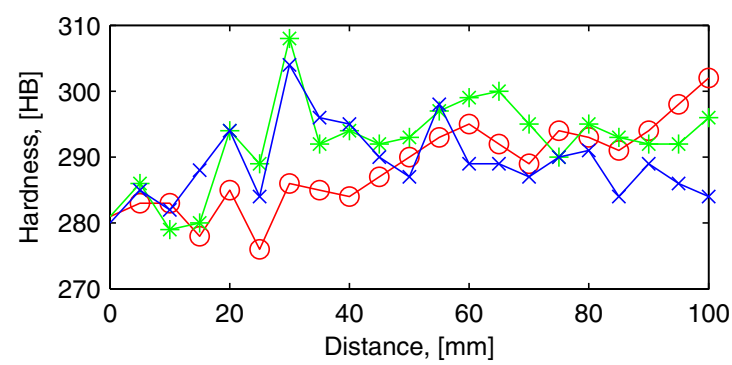

(a)

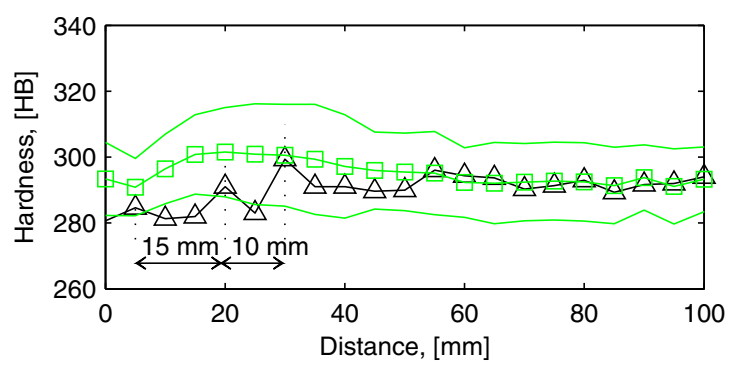

(b)

Fig. 15 Measured hardness after the discontinuity at the IRJ with damaged insulation layer $(\mathbf{a})$ along the inner $(\circ)$, middle $(*)$ and outer lines $(\times)$ indicated in Fig. 5(b), (b) the average of the three measurements $(\triangle)$, and the average at the IRJ baseline ( $\square$ )

mainly determine the dynamic response of the track [17, $26]$ and a gain in freedom results in a change in characteristic frequencies, such as the bending modes of sleepers [21]. Regarding the second possible frequency identified, it corresponds to the pin-pin resonance frequency of $1040 \mathrm{~Hz}$, the same as for the IRJ with broken fastening (see Fig. 13).

For the N3 configuration, the $Z$ statistic is also larger than the statistical limit $Z_{\text {lim }}$ approximately between 670 and $920 \mathrm{~Hz}$. In this frequency range, the receptance function has significantly higher values than the baseline receptance function. This means that the rail vibrates with larger amplitudes at these frequencies for the same input force. Thus, one should expect larger wheel-rail vibrations immediately after the gap when a wheel rolls over a IRJ with a damaged insulation layer than over a good IRJ.

\section{IRJ with Plasticity}

The third damaged IRJ examined is shown in Fig. 17. Neither the track components nor the end-post seemed to be damaged to the naked eye. The sleepers seemed to be properly supported by the ballast as the stones in the proximity of the IRJ were not white. The only deterioration sign was the plasticity of the rail top after the gap (see the close-up in Fig. 17).

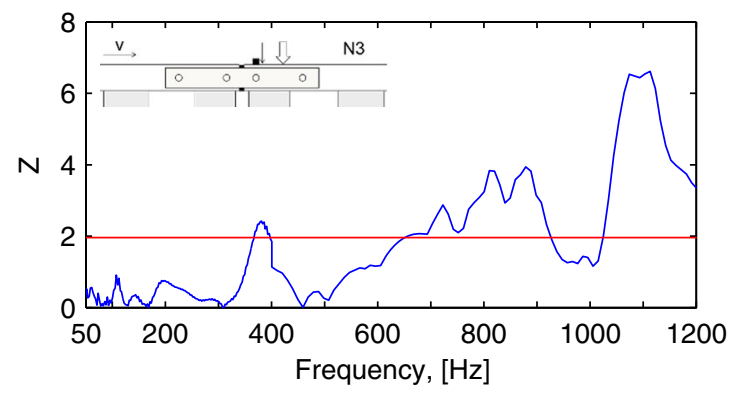

(a) N3 configuration

\section{Hammer measurement}

As the wavelength was clearly visible on the rail top, hardness measurements were not performed for this IRJ. Hammer test measurements, however, were carried out and they were compared to the IRJ baseline via the FRF-based statistical method. The corresponding $Z$ statistics are shown in Fig. 18. The $Z$ statistic crosses the statistical limit $Z_{\text {lim }}$ only at $470 \mathrm{~Hz}$ for the $\mathrm{N} 3$ configuration. $Z$ values smaller than the $Z$ values of the other two damaged IRJ were expected because rail top plastic deformation is a less severe damage than a broken fastening and a damaged insulation later. Therefore, lighter damage is closer to the baseline state resulting in a smaller $Z$ value.

An approximate wavelength of $34 \mathrm{~mm}$ was derived from the photos (see the close-up in Fig. 17). The frequency of the vibrations that arises when a train runs at a nominal speed of $140 \mathrm{~km} / \mathrm{h}$ over this wavelength is approximately $1040 \mathrm{~Hz}$, which is a frequency identified for the other two damaged IRJs. However, the $Z$ statistic at $1040 \mathrm{~Hz}$ is below the statistical limit $Z_{\text {lim }}$ for the IRJ with plasticity. The absence of this frequency indicates that the dynamic response of the IRJ is still statistically close to the IRJ baseline response. Thus, although the rail top is plastically deformed, the structure of the IRJ has not changed enough for hammer tests to detect the changes.

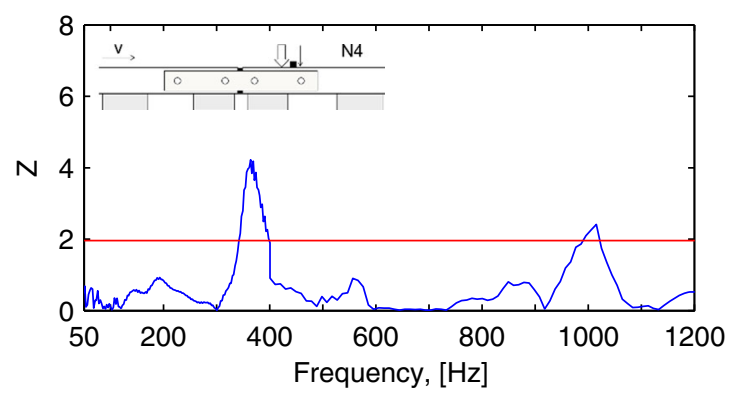

(b) N4 configuration

Fig. $16 Z$ test at the IRJ with broken fastening with (_) $Z_{\text {lim }}$, and (-) $Z$ at the IRJ with a damaged insulation layer 


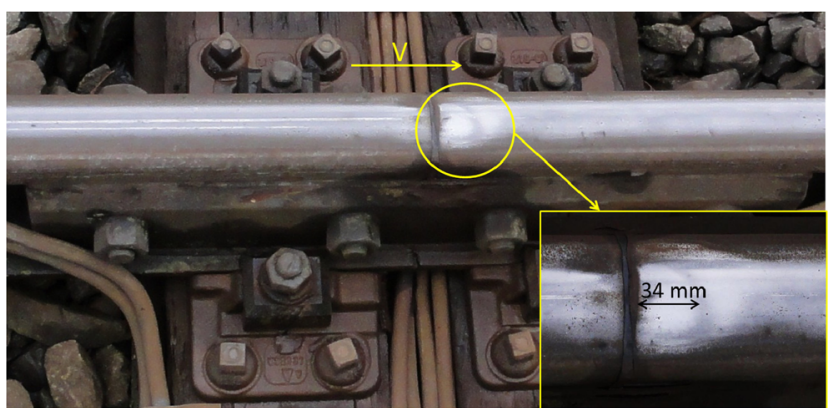

Fig. 17 An insulated rail joint with plasticity

\section{Discussion}

\section{IRJ Baseline Response Versus Damaged IRJ Response}

The damaged IRJs have two characteristic frequency bands in common in the frequency range of $50-1200 \mathrm{~Hz}$.

420-600 Hz: Between 420 and $600 \mathrm{~Hz}$, the frequency of $566 \mathrm{~Hz}$ is identified for the IRJ with broken fastening and the frequency of $470 \mathrm{~Hz}$ is identified for the IRJ with plastic deformation (see Figs. 13 and 18, respectively). The IRJ with damaged insulation layer shows a characteristic frequency at lower frequency (i.e. $380 \mathrm{~Hz}$ ) most probably because the structural differences (i.e. different plates) have significantly changed the characteristic frequencies of the IRJ. Regarding the IRJ baseline, the average receptance function shows two shallow depths at 470 and $566 \mathrm{~Hz}$ for the N3 configuration (see Fig. 9). The receptance value of these depths differ statistically for the damaged IRJs and the IRJ baseline; the difference could be caused by the changes in the rail, joint and support.

1000-1150 Hz: In this frequency band, the frequency of $1040 \mathrm{~Hz}$ has been identified via the FRF-based statistical method (see Figs. 13 and 16). This frequency is approximately the pin-pin resonance frequency of the test track site. Furthermore, the wavelengths on the rail tops measured with hardness tests or pictures correspond to vibrations in this frequency range for the nominal train speed of $140 \mathrm{~km} / \mathrm{h}$.

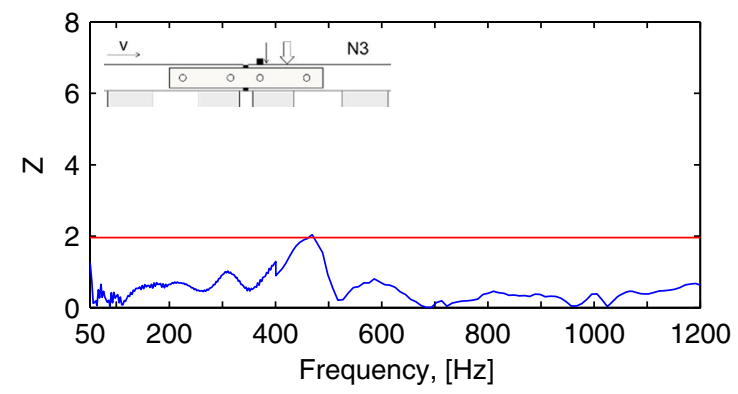

(a) $\mathrm{N} 3$ configuration
Table 1 Common characteristics frequency bands of the damaged IRJs identified via the FRF-based statistical method

\begin{tabular}{lll}
\hline Damage types of IRJs & $420-600 \mathrm{~Hz}$ & $1000-1150 \mathrm{~Hz}$ \\
\hline Broken fastening & $566 \mathrm{~Hz}$ & $1040 \mathrm{~Hz}$ \\
Damaged insulation layer & - & $1040 \mathrm{~Hz}$ \\
Plastic deformation & $470 \mathrm{~Hz}$ & $-\mathrm{Hz}$ \\
\hline
\end{tabular}

The identified possible characteristic frequencies of the damaged IRJs in the two frequency bands are summarized in Table 1. This analysis shows that it seems feasible to detect some damage conditions of IRJs by analyzing their frequency response. Furthermore, the comparison between different damaged IRJs suggests that monitoring the prominence of the dominant peak in the frequency range $1000-1150 \mathrm{~Hz}$ may help to predict the condition of IRJs. In "Comparison to a Vehicle-Borne Monitoring System" section, it is investigated if the information obtained from the hammer test can be employed for the assessment and monitoring of the condition of IRJs with vehicle-borne monitoring systems which are based on analyzing the dynamic behavior, such as axle box acceleration systems [38-40] and strain-gauge-instrumented wheelsets [41].

\section{Comparison to a Vehicle-Borne Monitoring System}

\section{The axle box acceleration ( $A B A)$ system}

ABA systems consist of accelerometers mounted on axle boxes, a GPS antenna for positioning and the recording of the vehicle speed [38-40]. The ABA system is a monitoring system that measures the response of the axle boxes to changes in the wheel-track structure. Depending on the origin of the response, different characteristic frequencies (also called signature tunes) can be found in the measured signals. Thus, by post-processing the measured accelerations in combination with the position and the vehicle speed, defects can be identified and their deterioration state can be assessed if the characteristic frequencies are known.

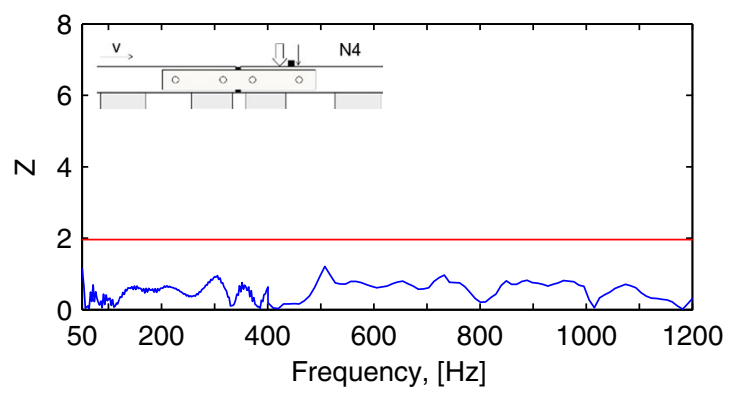

(b) N4 configuration

Fig. $18 Z$ test at the IRJ with broken fastening with (_) $Z_{\text {lim }}$, and (_) $Z$ at the IRJ with plasticity 
For instance, squats, which are a short wave defect on the rail top, can be automatically detected at an early stage by employing this method [39]. The automatic detection of track defects can be performed by using scale averaged wavelet power (SAWP). The SAWP measures the localized variations of wavelet power spectrum in a certain frequency bands and it is defined as the weighted sum of wavelet power spectrum over scales $s_{j_{1}}$ to $s_{j_{2}}$ [42]:

$\bar{W}_{n}^{2}=\frac{\delta j \delta t}{C_{\delta}} \sum_{j=j_{1}}^{j_{2}} \frac{\left|W_{n}\left(s_{j}\right)\right|^{2}}{s_{j}}$

where $\left|W_{n}\left(s_{j}\right)\right|^{2}$ is the wavelet power spectrum, $\delta j$ is a scale step, $\delta t$ is time step, $C_{\delta}$ is and empirically derived constant for each wavelet function.

\section{Potential to monitor IRJS}

ABA systems can be a suitable monitoring system for IRJs because impact between the wheel and the rail occur due to the presence of the discontinuity. Furthermore, ABA systems would examine the dynamic behavior of IRJs which changes depending on their damage state, as shown in "Damaged IRJs" section.

To develop a dynamic-response-based vehicle-borne monitoring system for IRJs, characteristic frequencies of damaged IRJ are required. For this purpose, the information obtained in this paper could be used and further completed, if the difference in the loading of the track (i.e. presence of a vehicle in the track) between the hammer test measurements and the ABA system does not influence the frequency bands related to damaged IRJs. The loading condition of the track may affect the identified characteristic frequency bands because some track components behave non-linearly

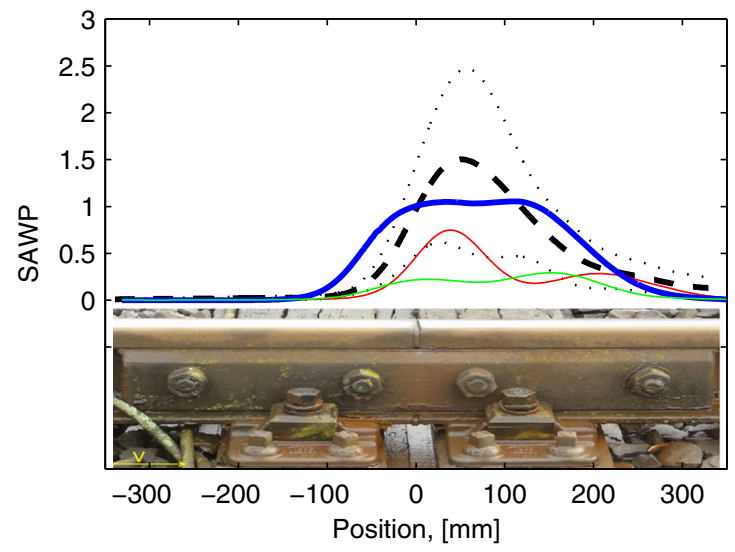

(a) $420-600 \mathrm{~Hz}$ when the track is loaded [43]. Thus, in the following section it is investigated if the frequency bands identified with the hammer test measurements can be employed to examine ABA signals for monitoring of IRJs.

\section{Measured ABA signals at the damaged IRJS}

The three damaged IRJs investigated were examined with an extensively validated ABA system [39]. The SAWP of the measured vertical ABA signals was calculated for the two frequency bands of $420-600 \mathrm{~Hz}$ and $1000-1150 \mathrm{~Hz}$ that were identified in the analysis of hammer test measurements. The SAWP values are shown in Fig. 19(a) and (b), respectively. Each figure displays the SAWP of the ABA measurements of the three investigated damaged IRJs and the ones of the IRJ baseline. The distance shown covers the length of the plates, from $-340 \mathrm{~mm}$ to $340 \mathrm{~mm}$, where $0 \mathrm{~mm}$ is the center of the end-post. Although the gap of the IRJ shown in the picture in Fig. 19 is centered with respect to the supports, the IRJ with the broken fastening and the IRJ with the damaged insulation layer were not centered (see Figs. 11 and 14, respectively).

The largest difference between the damaged IRJs and the IRJ baseline is found in the frequency band of 1000$1150 \mathrm{~Hz}$ (Fig. 19(b)). Whereas the ABA measurements at the IRJ baseline has SAWP values lower than 0.05 , the three damaged IRJ show local maxima larger than 0.15 . In the frequency range of 420-600 Hz (Fig. 19(a)), the maximum SAWP value decreases with increasing visual damage. This is, the largest SAWP value is obtained for the IRJ baseline, whereas the smallest SAWP value is obtained for the IRJ with the damaged insulation layer. By comparing the maximum SAWP values and considering the degree of visual damage, the IRJs can be divided into two groups (see Table 1). In the first group, the IRJ baseline and the IRJ with plasticity show a maximum SAWP value larger than 0.9 . In

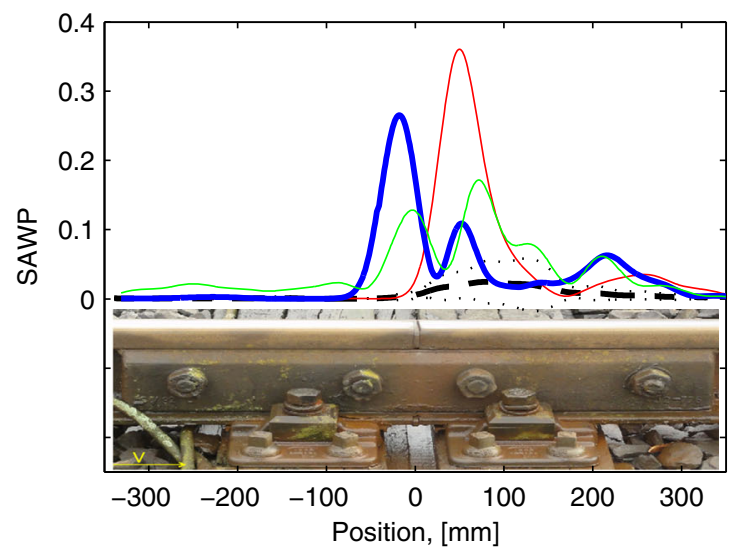

(b) $1000-1150 \mathrm{~Hz}$

Fig. 19 SAWP of the ABA signals along the IRJs: ( - — - ) the average SAWP of IRJ baseline, ( ...) one standard deviation with respect to the average SAWP, (-) the IRJ with the broken fastening, (-) the IRJ with the damaged insulation layer and ( - ) the IRJ with plasticity 
Table 2 Relations between maximum SAWP values and types of damage of IRJs

ABA measurements

$\begin{array}{ll}\text { Frequency band } & \begin{array}{l}\text { Maximum } \\ \text { SAWP }\end{array}\end{array}$

\begin{tabular}{lll}
\hline $420-600 \mathrm{~Hz}$ & $>0.9$ & $\begin{array}{l}\text { light deterioration (e.g. plasticity } \\
\text { on the rail top) }\end{array}$ \\
& $<0.8$ & $\begin{array}{l}\text { severe deterioration (e.g. broken } \\
\text { fastening, damaged insulation layer) } \\
\text { damaged (i.e. not-healthy) }\end{array}$ \\
$1000-1150 \mathrm{~Hz}$ & $>0.15$ &
\end{tabular}

the second group, the IRJ with a broken fastening and the IRJ with a damaged insulation layer displayed a maximum SAWP value lower than 0.8 .

The obtained information could be employed in the monitoring, prediction and prognosis of IRJ based on the presented analysis (Table 2). First, the SAWP value in the frequency band of 1000-1150 Hz could be used to detect damaged IRJs. Next, the SAWP value in the frequency band of $420-600 \mathrm{~Hz}$ could be employed for identifying the damage type. In future work, a larger set of damaged IRJs should be investigated to complete this study. With a statistically reliable number of damaged IRJ, characteristic frequencies of each damage type could be identified so that the damage types and state might be pin-pointed via ABA monitoring.

In summary, the analysis of SAWP values of the ABA measurements calculated in the frequency ranges identified from the hammer test measurements gives potentially useful information. The study shows the potential of combining these two measurements systems to contribute to the development of IRJ condition monitoring systems.

\section{Conclusions}

A feasibility study is presented to assess if the health condition of Insulated Rail Joints (IRJs) can be determined by analyzing their response to impact excitation. The impact excitation is performed with hammers of small and large size and by train wheels hitting the rail at the gap. The response was picked up by accelerometers on the rail head for the former case, and by accelerometers on the axle box of the train for the latter. The condition of IRJs was investigated by comparing the vertical dynamic behavior of damaged IRJs to a IRJ baseline response via the frequency response function (FRF) based statistical method. For this purpose, hammer test measurements were performed at IRJs of different damage states and a baseline was determined based on IRJs without visual deterioration to the naked eye (i.e. reference IRJs). Moreover, the hardness of the rail top immediately after the gap was measured, photos were taken and vehicle-borne acceleration measurements were performed.

First, the IRJ baseline response was studied. The analysis showed that the vertical dynamic behavior of the reference IRJs was not symmetrical to the discontinuity because the one-directional traffic changed considerably the receptance function at high frequency. For the case studied, the frequency range in which the frequency response was almost not changed and therefore can be used as baseline, was identified between 50 and $1200 \mathrm{~Hz}$. This study also showed that the dynamic response depends on the excitation configuration; in this paper, two receptance functions obtained from exciting the rail above the third bolt and above the fourth bolt were used. By fitting numerical models to the measured IRJ baseline curves, numerical IRJ models can be validated and parameters of the track in the proximity of a reference IRJ can be derived.

Second, three IRJs at different damage states were examined. By comparison to the IRJ baseline responses via the FRF-based statistical method, two frequency bands related to the damaged IRJs were derived independent of the type of damage (i.e. $420-600 \mathrm{~Hz}$ and $1000-1150 \mathrm{~Hz}$ for the IRJs investigated). At the highest frequency range, the identified frequency is the pin-pin resonance of the test track site; this phenomenon seems to fix the dominant wavelength of the hardness wave pattern on the rail top.

The feasibility study was completed by employing the frequency ranges derived from the hammer test to examine vehicle-borne axle box acceleration measurements which were performed at the same IRJs as for the hammer test. By comparing the scale averaged wavelet powers (SAWP) of the measured signals, it was found that the damaged IRJs differed significantly from the reference IRJ in the identified high frequency range. In the identified mid-frequency band, the maximum SAWP value decreased with increasing damage; this frequency range has the potential to be used for damage type assessment. In summary, the presented work shows the potential to monitor and assess the condition of IRJs by analyzing the responses to impact excited by hammer or by wheels of trains hitting the gap of IRJs. The monitoring of the dynamic response of IRJs may lead to the diagnosis and prognosis of their condition.

To complete and support the results, the extension of the current study to a larger set of damaged IRJs is part of future work. Hardness measurements of the rail top should be performed before and after the discontinuity because comparing the two sides may help assessing the condition of IRJs. In addition, measurements and numerical simulations could be combined to obtain a better understanding of the dynamic behavior of IRJs. By fitting simulations to measurements, numerical models can be validated. Then, numerical modal analysis can be performed to identify vibration modes and 
the influence of different parameters under controlled simulations can be investigated. Further investigation into the vibration modes occurring in the two possible characteristic frequency ranges related to IRJs may be of interest to pin-point locations and types of damage. This information may be useful for improved design and development of IRJs as well as for the development of monitoring systems and maintenance measures.

Acknowledgments This research was partially supported by the Basque Government of Spain (Grant No. BFI10). This work was also partially supported by the Dutch railway infrastructure manager ProRail, the Netherlands Organization for Scientific Research NWO and the Technology Foundation STW.

Open Access This article is distributed under the terms of the Creative Commons Attribution 4.0 International License (http:// creativecommons.org/licenses/by/4.0/), which permits unrestricted use, distribution, and reproduction in any medium, provided you give appropriate credit to the original author(s) and the source, provide a link to the Creative Commons license, and indicate if changes were made.

\section{References}

1. Pang T, Dhanasekar M (2006) Dynamic finite element analysis of the wheel-rail interaction adjacent to the insulated rail joints. 7th International Conference on Contact Mechanics and Wear of Wheel/rail Systems

2. Sandström J, Kabo E, Nissen A, Jansson F, Ekberg A, Lundén R (2012) Deterioration of insulated rail joints - a three-year field study. In: 9th Internation Conference on Contact Mechanics and Wear of Rail/Wheel Systems, Chengdu, China, pp 301-308

3. Wen Z, Tin X, Zhang W (2005) Contact-impact stress analysis of rail joint region using the dynamic finite element method. Wear 258(7-8):1301-1309

4. Bandula-Heva T, Dhanasekar M, Boyd P (2013) Experimental investigation of wheel/rail rolling contact at railhead edge. Exp Mech 53(6):943-957

5. Mayville R, Stringfellow R (1995) Numerical analysis of a railroad bolt hole fracture problem. Theor Appl Fract Mech 24(1):112

6. Sandström J, Ekberg A (2009) Numerical study of the mechanical deterioration of insulated rail joints. Proc Inst Mech Eng F J Rail Rapid Transit 223(3):265-273

7. Mandal NK, Dhanasekar M (2013) Sub-modelling for the ratchetting failure of insulated rail joints. Int J Mech Sci 75:110 122

8. Jenkins H, Stephenson J, Clayton G, Morland G, Lyon D (1974) Effect of track and vehicle parameters on wheel/rail vertical dynamic forces. Railw Eng J 3(1):2-16

9. Kabo E, Nielsen J, Ekberg A (2006) Prediction of dynamic traintrack interaction and subsequent material deterioration in the presence of insulated rail joints. Veh Syst Dyn 44(SUPPL. 1):718729

10. Kerr A, Cox J (1999) Analysis and tests of bonded insulated rail joints subjected to vertical wheel loads. Int J Mech Sci 41(10):1253-1272

11. Li Z, Zhao X, Dollevoet R, Molodova M (2008) Differential wear and plastic deformation as causes of squat at track local stiffness change combined with other track short defects. Veh Syst Dyn 46(SUPPL.1):237-246

12. Chen Y, Kuang J (2002) Contact stress variations near the insulated rail joints. Proc Inst Mech Eng F J Rail Rapid Transit 216(4):265-274

13. Wu T, Thompson D (2003) On the impact noise generation due to a wheel passing over rail joints. J Sound Vib 267(3):485496

14. Askarinejad H, Dhanasekar M, Cole C (2013) Assessing the effects of track input on the response of insulated rail joints using field experiments. Proc Inst Mech Eng F J Rail Rapid Transit 227(2):176-187

15. Dhanasekar M, Bayissa W (2012) Performance of square and inclined insulated rail joints based on field strain measurements. Proc Inst Mech Eng F J Rail Rapid Transit 226(2):140154

16. Zong N, Askarinejad H, Heva TB, Dhanasekar M (2013) Service condition of railroad corridors around the insulated rail joints. $\mathrm{J}$ Transp Eng 139(6):643-650

17. Grassie S, Gregory R, Harrison D, Johnson K (1982) Dynamic response of railway track to high frequency vertical excitation. J Mech Eng Sci 24(2):77-90

18. Kaewunruen S, Remennikov A (2008) An alternative rail pad tester for measuring dynamic properties of rail pads under large preloads. Exp Mech 48(1):55-64

19. Remennikov A, Kaewunruen S (2006) Experimental investigation on dynamic railway sleeper/ballast interaction. Exp Mech 46(1):57-66

20. Hiensch M, Nielsen J, Verheijen E (2002) Rail corrugation in the Netherlands - measurements and simulations. Wear 253(1-2):140 149

21. Oregui M, Li Z, Dollevoet R (2015) An investigation into the vertical dynamics of tracks with monoblock sleepers with a 3D finite element model. Accepted for publication in Proceedings of the Institution of Mechanical Engineers Part F: Journal of Rail and Rapid Transit

22. Thompson D, Vincent N (1995) Track dynamic behaviour at high frequencies. part 1: theoretical models and laboratory measurements. Veh Syst Dyn 24(Suppl):86-99

23. de Man A (2002) Dynatrack: a survey of dynamic railway track properties and their quality. PhD dissertation. Delft University of Technology

24. Bruël, Kjær (2014) 8206 impact hammer. http://www.bksv.com

25. PCB Piezotronics (2014) 086d50 large-sledge impulse hammer. http://www.pcb.com

26. Knothe K, Wu Y (1998) Receptance behaviour of railway track and subgrade. Arch Appl Mech 68(7-8):457-470

27. Bruël, Kjær (2013) Structural testing: Mechanical mobility measurements. http://www.bksv.com/library/primers

28. Montgomery DC (2009) Introduction to statistical quality control, 6th Edition. Wiley, Hoboken, New Jersey

29. Oregui M, Li Z, Dollevoet R (2015) Identification of characteristic frequencies of damaged railway tracks using field hammer test measurements. Mech Syst Signal Process 54:224 242

30. Oregui M, Li Z, Dollevoet R (2015) An investigation into the modeling of railway fastening. Int J Mech Sci 92:1-11

31. Thompson D (1993) Wheel-rail noise generation, part iii: Rail vibration. J Sound Vib 161(3):421-446

32. Grassie S (2009) Rail corrugation: Characteristics, causes, and treatments. Proc Inst Mech Eng F J Rail Rapid Transit 223(6):581596

33. Fassois SD, Sakellariou JS (2007) Time-series methods for fault detection and identification in vibrating structures. Philos Trans $\mathrm{R}$ Soc A Math Phys Eng Sci 365(1851):411-448 
34. Kopsaftopoulos F, Fassois S (2010) Vibration based health monitoring for a lightweight truss structure: Experimental assessment of several statistical time series methods. Mech Syst Signal Process 24(7): 1977-1997

35. Oppenheim AV, Schafer RW (1975) Digital Signal Processing. Prentice-Hall, Englewood Cliffs, New Jersey

36. Bendat JS (1980) Engineering applications of correlation and spectral analysis. Wiley, Hoboken, New Jersey

37. Li Z, Dollevoet R, Molodova M, Zhao X (2011) Squat growthsome observations and the validation of numerical predictions. Wear 271(1-2): 148-157

38. Bocciolone M, Caprioli A, Cigada A, Collina A (2007) A measurement system for quick rail inspection and effective track maintenance strategy. Mech Syst Signal Process 21(3):1242-1254
39. Molodova M, Li Z, Núñez A, Dollevoet R (2014) Automatic detection of squats in the railway infrastructures. IEEE Trans Intell Transp Syst 15(5):1980-1990

40. Weston P, Ling C, Goodman C, Roberts C, Li P, Goodall R (2007) Monitoring lateral track irregularity from in-service railway vehic les. Proc Inst Mech Eng F J Rail Rapid Transit 221(1):89-100

41. Kassa E, Nielsen J (2008) Dynamic interaction between train and railway turnout: Full-scale field test and validation of simulation models. Veh Syst Dyn 46(SUPPL.1):521-534

42. Torrence C, Compo G (1998) A practical guide to wavelet analysis. Bull Am Meteorol Soc 79(1):61-78

43. Wu T, Thompson D (1999) The effects of local preload on the foundation stiffness and vertical vibration of railway track. J Sound Vib 219(5):881-904 